\title{
Liquidity Skewness in the London Stock Exchange
}

\author{
Tsung-Han Hsieh* Youwei $\mathrm{Li}^{\dagger} \quad$ Donal G. McKillop ${ }^{\ddagger}$ \\ Yuliang $\mathrm{Wu}^{\S}$
}

Acknowledgement: Youwei Li acknowledges the support of National Natural Science Foundation of China (No.71571197).

*Department of Marketing and Distribution Management, Tajen University, Taiwan. Email: thhsieh@hotmail.com.

†Queen's Management School, Queen’s University Belfast, Belfast, BT9 5FE, United Kingdom. Email: y.li@qub.ac.uk.

‡Queen’s Management School, Queen’s University Belfast, Belfast, BT9 5FE, United Kingdom. Email: dg.mckillop@qub.ac.uk.

${ }^{\S}$ School of Management, The University of Bradford, Emm Ln, Bradford, BD9 4JL, United Kingdom. Email: Y.Wu20@bradford.ac.uk. 


\begin{abstract}
We study liquidity on the London Stock Exchange. We find that the average bid-ask spread declines, but that the skewness of the spread increases. These results are robust to firm size, trading volume and price level. Our findings hold when the bid-ask spread is estimated utilising high frequency data. We find that the bid-ask spread prior to earnings announcements dates is significantly higher than that of post earnings announcements, suggesting that asymmetric information has driven the increase in liquidity skewness. We also find that the effect of earnings announcements is more pronounced in the 2007 global financial crisis, consistent with the notion that extreme market downturns amplify asymmetric information. Our overall evidence also implies that increased competition and transparent trading environments limit market makers' abilities to cross-subsidize bid-ask spreads between periods of high and low levels of asymmetric information.
\end{abstract}

Keywords: Asymmetric information; Bid-ask spread; Liquidity; London Stock Exchange; Skewness

JEL Classification: G01; G12; G14 


\section{Introduction}

Liquidity is a central feature of securities and financial markets. Liquid financial markets allow market participants to trade large amounts of securities without price impact and at a low cost. Amihud and Mendelson (1986) and Amihud (2002) find that liquidity affects the expected return of assets. Practically, liquidity plays an important role in high frequency trading, which expanded vastly in the last decade (O'Hara, 2014). As high frequency trading is more sensitive to transaction costs, traders tend to demand more liquid assets (Bowen, Hutchinson, and O'Sullivan, 2010). Also, central banks, financial regulators and policy makers are concerned with market liquidity and its dynamics over time given its importance in the promotion of financial stability (Pelizzon et al. 2016).

In recent decades stock market liquidity has significantly increased. The improvement is largely due to the adoption of new computing and communication technologies. However, it is also due arguably to increased competition between multilateral trading facilities and exchanges, transparent pre-trade and post-trade information, the reduction in minimum tick size, and the clamp down on market abuse and insider trading.

Liquidity can be measured by the cost of immediate execution: the bid-ask spread. Traders can submit limit orders awaiting execution or pay the bid-ask spread premium to execute market orders immediately. The quoted ask price reflects a premium required for immediate buying and the bid price contains a concession 
for immediate selling. Hence, the skewness of bid-ask spreads and its variation over time helps us gain insights into the pattern of trading costs. Using the bid-ask spread as a proxy for liquidity, the aim of this paper is to investigate the distribution and dynamics of liquidity.

Early work on the dynamics of liquidity suggests that changes in liquidity skewness can be attributed to increased competition between market markers. Glosten and Milgrom (1985) argue that the specialist with monopoly power can set the bidask spread more flexibly than those faced with a more competitive environment. Consistent with Glosten and Milgrom (1985), Roll and Subrahmanyam (2010) further contend that the skewness of bid-ask spreads is driven by competition among market makers who are less able to cross-subsidize bid-ask spreads during periods of high and low levels of asymmetric information. In periods of low level of asymmetric information market makers with monopoly power are more able to raise spreads and to cover increased losses to informed agents than during periods of high level of asymmetric information. The decline in cross subsidisation in a competitive market contrasts with that of a 'monopolistic' regime in which market makers can flexibly set bid-ask spreads. Increased market competitiveness should force market makers to break even on each transaction across periods of high and low levels of asymmetric information. Consistent with this notion, Bessembinder (2003) show that increased competition and low tick size lead to a clustering of small spreads. However, the bid-ask spread can be positively skewed when the market is illiquid and information 
asymmetry is high (Pelizzon et al. 2016). Roll and Subrahmanyam (2010) find that bid-ask spreads in the U.S. equity market have declined, with the spreads also becoming increasingly right-skewed during the period of 1993-2007. Roll and Subrahmanyam (2010) attribute liquidity skewness to asymmetric information. Their findings show that liquidity skewness is positively correlated with asymmetric information between firms and investors proxied by institutional holdings and analyst following.

This paper investigates liquidity skewness in the London Stock Exchange (LSE). The LSE is the third largest stock market in the world and its institutional setting is different from the U.S. markets. Our study is the first out-of-sample test of the findings of Roll and Subrahmanyam (2010). Our dataset includes both daily bidask spreads and high frequency spreads in the LSE from September 1997 to March 2009. Our paper is distinguished from previous studies in two aspects. First, our sample period covers the two biggest market declines in recent times, namely the collapse of the dot-com bubble (2000-2002) and the start of the global financial crisis (2007-2008). Prior studies show that extreme market downturns significantly reduce liquidity in assets such as government bonds and stocks (Pelizzon et al. 2016; Hameed et al. 2010; Brummermeier and Pedersen, 2009). These studies would suggest that liquidity should exhibit different patterns over our sample period. Also, extreme market downturns affect investors' funding capital and, therefore, are likely to widen bid-ask spreads compared to normal times (Brummermeier and Pedersen, 
2009). This notion implies that the bid-ask spread is likely to be right-skewed in periods of crisis. Second, the LSE is subject to EU legislation. Specifically, the LSE adopted the Market in Financial Instrument Directive (MiFID) in November 2007. MiFID has significantly changed European equity markets, it has increased market competition and transparency. Market makers are required to disclose bid and ask prices, volume and the depth of trading to the general public before and after each transaction in a timely manner. Our sample period covers the adoption of MiFID and consequently allows us to consider the initial impact of MiFID on the LSE.

Our results show that average bid-ask spreads in the LSE decrease significantly throughout our sample period, suggesting a substantial decline in trading costs in the LSE. The bid-ask spread reaches its lowest level between 2008 and 2009, consistent with the anticipated impact of MiFID. However, the skewness of bidask spreads has increased over our sample period. This evidence is consistent with the notion that increased competition and enhanced trading environments limit the power of market makers to flexibly set bid-ask spreads over time. Our findings further show that the skewness of bid-ask spreads peaks when the dot-com bubble burst (2000-2002), and at the outset of the global financial crisis (2007-2008). The results imply that extreme market downturns have a significantly negative effect on market liquidity, consistent with the recent findings of Pelizzon et al. (2016). We also show that the bid-ask spread prior to earnings announcements is significantly higher than the spread in the post earning announcements period. Our evidence 
that the bid-ask spread is high in extreme market downturns and prior to earnings announcements is consistent with the asymmetric information based explanation for the skewness of liquidity. Our main findings are robust to firm size, trading volume and price level. Finally, our cross-sectional analysis confirms a positive relationship between earnings announcements and the skewness of bid-ask spreads in the 2007 global financial crisis. This result implies that extreme market downturns amplify asymmetric information on the LSE.

The rest of this paper is organised as follows: Section 2 describes the institutional background of the London Stock Exchange and the data set we used in this study. Section 3 provides the results. Section 4 concludes the paper.

\section{The London Stock Exchange and the Data}

\subsection{The London Stock Exchange}

The London Stock Exchange is one of the oldest stock exchanges in the world and has its history back to 1698. Today, the LSE is the third largest stock trading venue in the world with a combined market capitalization of over $£ 1.1$ trillion on its Main Market $^{1}$, just behind NASDAQ and NYSE Euronext. A wide range of securities, including equity, fixed income, derivatives, exchange traded funds, structured products and covered warrants, are traded in the LSE. Stocks are traded in the Main Market and Alternative Investment Market (AIM) of the Exchange. Derivatives are

\footnotetext{
${ }^{1}$ Statistics from http://www.londonstockexchange.com/statistics/markets/main-market/mainmarket.htm.
} 
traded in the EDX London exchange.

There exists several electronic trading platforms in the LSE, each suited to a specific type of security. Most liquid stocks are traded on the Stock Exchange Electronic Trading System (SETS) which was created in October 1997. This covers all FTSE 100 companies, FTSE 100 Reserves and most liquid FTSE 250 companies. In SETS the average daily number of trades in 2008 was 763,286 , and the average daily value traded was $£ 8.1$ billion $^{2}$. Our empirical research concentrates on SETS. SETS, as an electronic limit order book trading platform, allows market participants to submit orders to buy or sell stocks and to execute against existing orders. Market participants can observe each stock's trading statistics, including recent transaction prices and the state of the order book, through electronic screens. The SETS trading day is split into three periods ${ }^{3}$ : an opening auction period, a continuous trading period and a closing auction period. The opening auction starts at 7:50 and ends at 8:00. The closing auction starts at 16:30 and ends at 16:35. A number of different types of orders can be submitted to the SETS order book. ${ }^{4}$

\footnotetext{
${ }^{2}$ Calculated according to statistics from http://www.londonstockexchange.com/statistics /historic/secondary-markets/secondary-markets.htm.

${ }^{3}$ The LSE introduced an intra-day auction in March 2016.

${ }^{4}$ In this study, the dataset covers the period from 1997 to 2009, the type of orders traded during this period include market orders, limit orders, iceberg orders, at best orders, execute or eliminate orders, and fill or kill orders. In recent years, the type of orders has changed due to a significant improvement in latency. For the latest type of orders, see http://www.lseg.com/areas-expertise/ourmarkets/london-stock-exchange/equities-markets/trading-services/domestic-trading-services/sets.
} 


\subsection{The Data}

The daily data was obtained from Datastream and includes daily bid-ask spreads between September 1996 and March 2009. This sample period covers the the dotcom bubble (2000-2002) and the start of the global financial crisis (2007-2008). Our sample stocks are traded in SETS. We exclude investment trust companies. We use both quoted bid-ask spreads and proportional bid-ask spreads. The latter measures trading costs on a relative basis which is the difference between the ask and bid prices divided by the mid-point of the two prices.

We also examine bid-ask spreads using high frequency data from the LSE for the period 1997 to 2009. The high frequency data consists of the 'tick and best price' data and the 'historical order book rebuild' data. We use the following criteria to eliminate high frequency noise from individual stocks: (1) the stock price must not be lower than 10p and not higher than $£ 999.99$; (2) each stock must last 48 months over our data period (September 1996 to March 2009) with valid quotations within

market opening hours; (3) the price of a stock in the LSE database must have a corresponding price record on Datastream. After the implementation of the above rules, the data set extended to 1,600 stocks and more than 528 million trades.

For selected stocks, we exclude trades or quotes that are booked during opening and closing auction periods, and that are out of sequence. To determine the direction of trades, the Lee and Ready (1991) algorithm is applied to match the trading data with the best preceding quote within 5 seconds. In the Lee and Ready algorithm, 
a buy order is classified when its transaction price is above the midquote; while a sell order is when the transaction price is below the midquote. The 'tick test' is applied to those trades where the transaction price falls at the midpoint between the bid and ask quote. A trade is classified as a buy order if the strike price is higher than the previous trade price. While a trade is classified as a sell order if the price is lower than the previous transaction price. Anomalous trades are also omitted. We consider the following trades to be anomalies: (1) trades with negative bid-ask spreads; (2) proportional quoted spreads $>20 \%$; (3) quoted spreads $>£ 5.00$. Following the procedure in Hameed et al. (2010), we calculate the proportional quoted spread (QSPR) by dividing the difference between ask and bid quotes by their midquote. Daily QSPRs are then aggregated by averaging spreads for each day. Finally, our earnings announcement data is obtained from Thomson One Banker.

\section{Empirical Results}

\subsection{Summary Statistics}

Table 1 reports our preliminary results. Panel A and B provide mean, standard deviation and skewness for proportional spreads and quoted spreads. The statistics are reported on a year-by-year basis. For example, the statistics for 1997 are calculated from September 2006 to August 1997. The same rule is applied in other years with the exception of 2009 which covers the period from September 2008 to March 2009. 
Panel A shows that the mean of proportional quoted spreads increases substantially between 1996 and 2003 and then slowly decreases in the following years. Between 2002 and 2003, the average of proportional spreads has larger values than other years, suggesting that the collapse of the dot-com bubble had an adverse impact on liquidity. However, the skewness of proportional quoted spreads has significantly increased over the sample period. The last row in Panel A shows that the skewness of proportional quoted spreads is significantly different between 1997 and 2009. The skewness of the spreads in 2002 and 2003 is higher than in preceding years, implying that the bursting of the dot-com bubble caused the bid-ask spread to become positively skewed. Interestingly, a similar effect repeats in 2008 when the skewness of proportional bid-ask spreads reaches a peak (1.16). We also plot the skewness of proportional quoted spreads in Fig 1. The graph depicts a pattern of upward drift over time. Two of the spikes in spread skewness coincides respectively with the collapse of the dot-come bubble around 2001 and the global financial crisis in 2008 .

In Panel B, the average of quoted spreads has the largest values in 2000 and 2001 and sharply declines in the following years. The substantial decline in the quoted bid-ask spreads since 2000 indicates a reduction in trading costs and an improvement in liquidity on the LSE. The improved trading transparency may contribute to changes in liquidity. Consistent with this conjecture, in the period 2008 to 2009, the quoted spreads have reached historical low levels. The evidence suggests that 
MiFID implemented in 2007 has improved market quality on the LSE. Similar to Panel A, we find that the skewness of quoted spreads has dramatically increased over the sample period. Once again, the skewness reaches the highest level in 2008 at 1.1263 , consistent with extreme negative market conditions being responsible for the skewness of bid-ask spreads. Our evidence of increasing skewness of bid-ask spreads also suggests that market makers become less able to influence bid and ask prices over time in line with regulatory initiatives to promote a fair and transparent trading environment. 
Table 1: Statistics of Annual Proportional Quoted Spread and Quoted Spreads

This table depicts summary statistics for the annual proportional quoted spreads and the raw annual quoted spreads for all stocks listed on the LSE. Statistics are calculated for each stock for each year ending at the 31st August. Daily bid-ask spreads for each stock are obtained from Datastream. The individual statistics are averaged on an equally-weighted basis to form the results presented in this table.

\begin{tabular}{|c|c|c|c|c|}
\hline Year & Mean & Std & Skewness & Number of firms \\
\hline \multicolumn{5}{|c|}{ Panel A: Statistics for proportional quoted spreads } \\
\hline $1997^{\mathrm{a}}$ & 0.0391 & 0.0144 & 0.1503 & 2409 \\
\hline 1998 & 0.0408 & 0.0165 & 0.4414 & 2499 \\
\hline 1999 & 0.0453 & 0.0195 & 0.3677 & 2428 \\
\hline 2000 & 0.0451 & 0.0197 & 0.3419 & 2468 \\
\hline 2001 & 0.0483 & 0.0222 & 0.4051 & 2483 \\
\hline 2002 & 0.0521 & 0.0266 & 0.6121 & 2398 \\
\hline 2003 & 0.0530 & 0.0279 & 0.6858 & 2201 \\
\hline 2004 & 0.0484 & 0.0217 & 0.4350 & 2273 \\
\hline 2005 & 0.0473 & 0.0225 & 0.6411 & 2538 \\
\hline 2006 & 0.0458 & 0.0239 & 0.7934 & 2712 \\
\hline 2007 & 0.0443 & 0.0231 & 0.7813 & 2732 \\
\hline 2008 & 0.0450 & 0.0247 & 1.1648 & 2587 \\
\hline $2009^{\mathrm{b}}$ & 0.0494 & 0.0337 & 1.0464 & 2228 \\
\hline $\begin{array}{l}H_{0} 2009-19970.0103 \\
t-\text { statistics }\end{array}$ & $\begin{array}{c}0.0193 \\
(10.1202) \\
* * *\end{array}$ & $\begin{array}{c}0.8961 \\
(31.5858) \\
* * *\end{array}$ & $\begin{array}{c}(19.9259) \\
* * *\end{array}$ & \\
\hline \multicolumn{5}{|c|}{ Panel B: Statistics for quoted spreads } \\
\hline 1997 & 7.3267 & 2.5240 & -0.1137 & 2409 \\
\hline 1998 & 7.7961 & 3.0091 & 0.1369 & 2499 \\
\hline 1999 & 7.4884 & 2.7794 & 0.0676 & 2428 \\
\hline 2000 & 10.4031 & 5.4856 & 0.0778 & 2468 \\
\hline 2001 & 9.5400 & 4.8923 & 0.2207 & 2483 \\
\hline 2002 & 7.2040 & 3.6280 & 0.3708 & 2398 \\
\hline 2003 & 5.9413 & 2.6651 & 0.5930 & 2201 \\
\hline 2004 & 6.4784 & 2.8401 & 0.2786 & 2273 \\
\hline 2005 & 6.1564 & 2.9987 & 0.5319 & 2538 \\
\hline 2006 & 5.9351 & 3.1623 & 0.7020 & 2712 \\
\hline 2007 & 5.8649 & 3.2228 & 0.7068 & 2732 \\
\hline 2008 & 4.9568 & 2.4989 & 1.1263 & 2587 \\
\hline 2009 & 4.1696 & 2.4023 & 1.0157 & 2228 \\
\hline$H_{0} 2009-1997$ & -3.1571 & -0.1217 & 1.1294 & \\
\hline \multirow[t]{2}{*}{$t-$ statistics } & $(-5.3897)$ & $(-0.4070)$ & $(21.8812)$ & \\
\hline & 0.9999 & 0.6580 & $* * *$ & $* * *: \mathrm{p}<0.01$ \\
\hline
\end{tabular}

a The data set commences from September 1996. The first row records statistics for September 1996 to August 1997 and the following rows comply with the same rule.

b The data set ends in March 2009 and the last row covers the period from September 2008 to March 2009. 


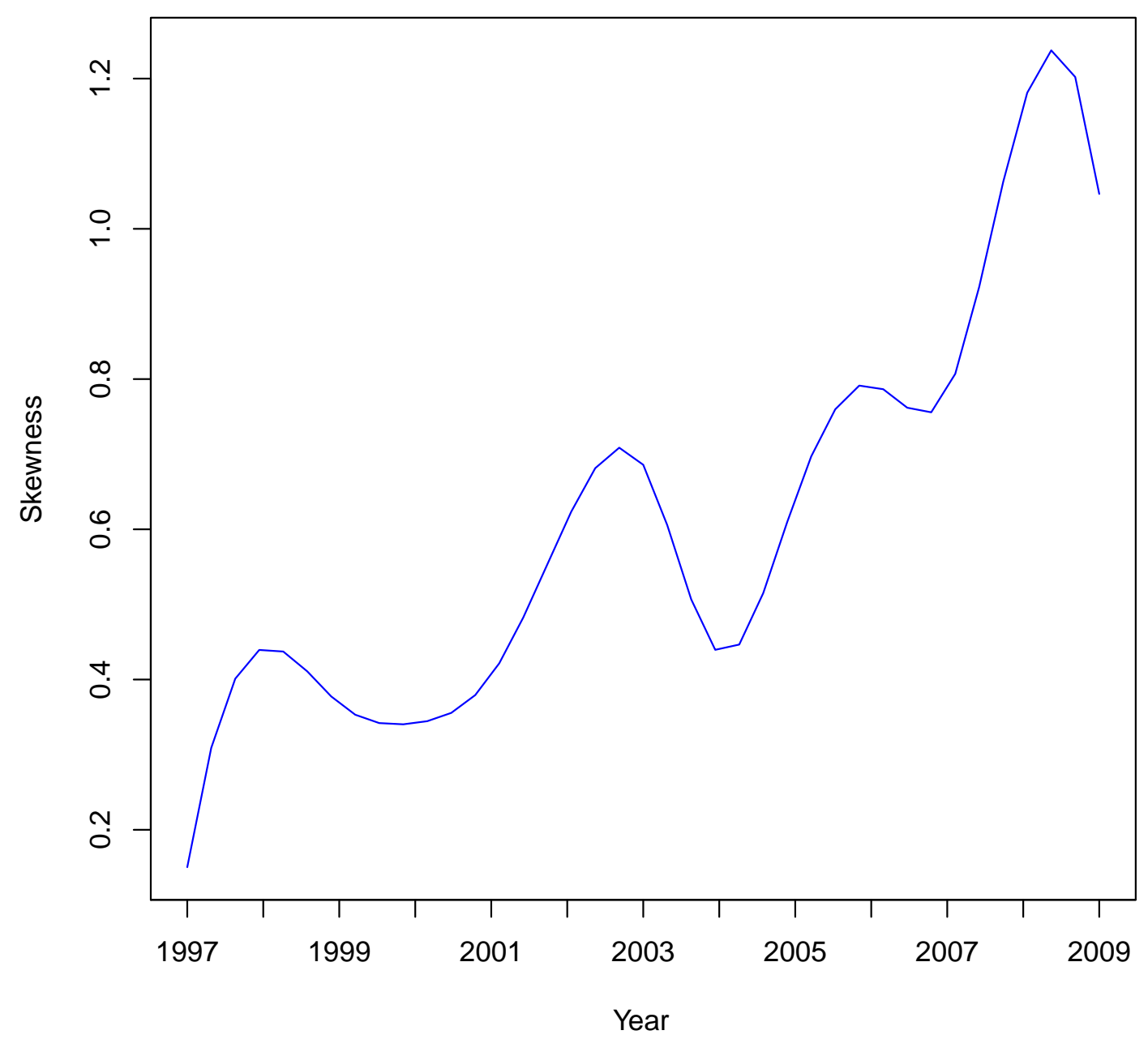

Figure 1: The annual proportional quoted spread skewness.

The skewness for proportional quoted spreads is calculated for all stocks listed in the LSE. The skewness is calculated for each stock for each year ended on 31st August from the corresponding daily data in Datastream, with the annual skewness calculated as the equallyweighted average skewness over all stocks. 


\subsection{Liquidity Skewness by Market Capitalisation, Volume, and Price}

Small-cap companies are usually characterized by small market capitalization, low trading volume and low prices. They are additionally more prone to liquidity risk, therefore, they have wider bid-ask spreads. To better understand the dynamics of the skewness of spreads, we examine the skewness of the proportional quoted spread across market capitalisation, trading volume, and price level. We rank firms by their market capitalisation, trading volume, and price level respectively; then for each we calculate the skewness of proportional quoted spreads. This information is presented by quartile in Table 2 .

Panel A reports the skewness of proportional quoted spreads conditional upon firm size. In the lowest size quartile, the skewness steadily increases from 2000 to 2003. Subsequently, it drops in 2004 and then increases again with a peak in 2009. In the second size quartile, we find that the overall trend is that of a modest increase in skewness. A similar pattern appears in the third size quartile. In the highest size quartile, the results show that skewness spikes in 2000 and 2008. This evidence is consistent with extreme market downturns driving the positive skewness of bidask spreads. In addition, the magnitude of skewness is greatest in the highest size quartile. The mean tests at the bottom of Panel A indicate that the skewness of bid-ask spreads significantly increases over time and across size quartiles.

In Panel B and C, we report the skewness of bid-ask spread conditioning upon 
trading volume and price level, respectively. The results show that the skewness across trading volume and price levels exhibits similar patterns to those in Panel A. More specifically, heavily traded and high-priced stocks have more right-skewed spreads than their counterparts. In general, there is a significant increase in the skewness from the first to the last sample years. In addition, large, frequently traded and high priced stocks all have the largest skewness in 2008 (i.e. 3.36, 3.02 and 2.42 in Panel A, B and C, respectively), suggesting that the 2007 global financial crisis drives the skewness of liquidity. In sum, we find that increased skewness of bid-ask spreads is neither a small-cap phenomenon nor a phenomenon of thinly-traded and low-priced stocks. 
Table 2: Skewness of proportional spreads by market capitalisation, market volume, and price level

The skewness of proportional spreads by categories. Panel A is the liquidity skewness by market capitalisation. Panel B depicts the liquidity skewness by volume and Panel $\mathrm{C}$ shows the liquidity skewness by the market price for each year which is calculated from the beginning of the previous September until the end of the current August for each year. The skewness is calculated for individual stocks during each year, then we calculate the equally-weighted average for that year.

\begin{tabular}{lllll}
\hline \multirow{2}{*}{ Year } & \multicolumn{4}{c}{ Size quartile } \\
\cline { 2 - 5 } & Smallest & 2nd & 3rd & Largest \\
\hline \multicolumn{4}{c}{ Panel A: Liquidity skewness by market capitalisation } \\
1997 & 0.0555 & -0.0110 & 0.1153 & 0.2658 \\
1998 & 0.0500 & 0.0600 & 0.1621 & 1.2912 \\
1999 & 0.2550 & 0.1632 & 0.2351 & 0.9778 \\
2000 & -0.1424 & 0.0782 & 0.1901 & 1.5988 \\
2001 & 0.2348 & 0.0698 & 0.2614 & 1.2658 \\
2002 & 0.5718 & 0.2432 & 0.3102 & 1.3455 \\
2003 & 1.1214 & 0.1399 & 0.1348 & 1.2899 \\
2004 & 0.4649 & 0.0076 & 0.1170 & 1.2878 \\
2005 & 0.5669 & -0.0037 & 0.4228 & 2.0521 \\
2006 & 0.8573 & 0.0775 & 0.8294 & 2.0174 \\
2007 & 0.5731 & 0.1456 & 0.8100 & 1.9921 \\
2008 & 0.7238 & 0.2877 & 0.5924 & 3.3651 \\
2009 & 1.5195 & 0.2769 & 0.3978 & 2.0727 \\
$2009-1997$ & 1.4641 & 0.2878 & 0.2825 & 1.8069 \\
$(t-$ statistics $)$ & 10.0863 & 9.8400 & 9.0198 & 12.2256 \\
$p-$ value & $(<0.001)$ & $(<0.001)$ & $(<0.001)$ & $(<0.001)$ \\
df & 416 & 475 & 483 & 489 \\
\hline
\end{tabular}

continue... 
Table 2: Continued

\begin{tabular}{|c|c|c|c|c|}
\hline \multirow[t]{2}{*}{ Year } & \multicolumn{4}{|c|}{ Volume quartile } \\
\hline & Smallest & $2 \mathrm{nd}$ & $3 \mathrm{rd}$ & Largest \\
\hline \multicolumn{5}{|c|}{ Panel B: Liquidity skewness by market volume } \\
\hline 1997 & 0.1772 & 0.1786 & 0.2971 & 0.3750 \\
\hline 1998 & 0.3318 & 0.2528 & 0.4335 & 2.0342 \\
\hline 1999 & 0.1612 & 0.3272 & 0.3406 & 1.3394 \\
\hline 2000 & -0.1794 & 0.1881 & 0.2683 & 1.7914 \\
\hline 2001 & 0.3729 & 0.2495 & 0.3364 & 1.4334 \\
\hline 2002 & 0.4681 & 0.3852 & 0.4685 & 1.6039 \\
\hline 2003 & 0.5210 & 0.3368 & 0.5283 & 1.3120 \\
\hline 2004 & 0.3950 & 0.0598 & 0.2639 & 1.1527 \\
\hline 2005 & 0.3159 & 0.2852 & 0.6734 & 1.6897 \\
\hline 2006 & 0.4033 & 0.5698 & 1.1003 & 1.6373 \\
\hline 2007 & 0.2182 & 0.3907 & 1.0485 & 1.8208 \\
\hline 2008 & 0.4271 & 0.4433 & 0.8604 & 3.0239 \\
\hline 2009 & 0.7976 & 0.6092 & 0.7878 & 1.9287 \\
\hline 2009-1997 & 0.6204 & 0.4306 & 0.4907 & 1.5538 \\
\hline$(t-$ statistics $)$ & 10.0754 & 13.3123 & 10.5453 & 15.4481 \\
\hline (p-value) & $(<0.001)$ & $(<0.001)$ & $(<0.001)$ & $(<0.001)$ \\
\hline \multirow[t]{2}{*}{ df } & 379 & 431 & 429 & 458 \\
\hline & \multicolumn{4}{|c|}{ Price quartile } \\
\hline \multicolumn{5}{|c|}{ Panel C: Liquidity skewness by price level } \\
\hline 1997 & 0.3877 & 0.1278 & 0.0763 & 0.0789 \\
\hline 1998 & 0.6605 & 0.0962 & 0.1751 & 0.9495 \\
\hline 1999 & 0.3844 & 0.2276 & 0.2376 & 0.7157 \\
\hline 2000 & 0.0758 & 0.0708 & 0.3861 & 1.0381 \\
\hline 2001 & 0.2738 & 0.1439 & 0.3973 & 0.8748 \\
\hline 2002 & 0.6062 & 0.4000 & 0.4320 & 1.0807 \\
\hline 2003 & 1.0968 & 0.4407 & 0.4446 & 0.9356 \\
\hline 2004 & 0.4361 & 0.2164 & 0.3405 & 0.9066 \\
\hline 2005 & 0.6444 & 0.3296 & 0.6515 & 1.3354 \\
\hline 2006 & 0.9506 & 0.3798 & 0.8543 & 1.4506 \\
\hline 2007 & 0.7251 & 0.3364 & 0.7243 & 1.5210 \\
\hline 2008 & 0.9201 & 0.3698 & 0.8605 & 2.4245 \\
\hline 2009 & 1.5167 & 0.5776 & 0.6209 & 1.6234 \\
\hline 2009-1997 & 1.1290 & 0.4498 & 0.5446 & 1.5445 \\
\hline$(t-$ statistics $)$ & 4.9478 & 9.0321 & 11.3178 & 12.4618 \\
\hline (p-value) & $(<0.001)$ & $(<0.001)$ & $(<0.001)$ & $(<0.001)$ \\
\hline df & 480 & 600 & 566 & 567 \\
\hline
\end{tabular}




\subsection{Liquidity Skewness in High-Frequency Database}

We now examine the skewness of quoted spreads and proportional quoted spreads using high frequency data from September 1996 to March 2009. To calculate the average skewness on an annual basis, we first average spreads within a day to obtain spreads for each stock. Second, we compute the skewness of daily spread for every stock in each year. Finally, we calculate the average of the skewness for all sample stocks on an annual basis. Table 3 and Figure 2 report and plot the average skewness of quoted and proportional quoted spreads, respectively.

Table 3 shows that the skewness of quoted and proportional spreads have both increased over time. The last row also shows that the skewness is significantly different between 1997 and 2009. For proportional spreads, the skewness in 2002 and 2008 is 0.72 and 1.16, respectively, implying that the decline in the market during these periods significantly constrained the ability of market makers to provide liquidity. Figure 2 shows that the two spreads share a very similar pattern of upward drifts over time. In addition, two spikes appear in 2002 and 2008, consistent with the previous findings based on daily data. In general the finding of increased skewness of bid-ask spreads is consistent for both daily data and high frequency data. 
Table 3: Skewness on the London Stock Exchange in High Frequency Data

This table shows the London Stock Exchange intraday skewness for each year. The quoted spreads are linked to corresponding transactions in the tick-by-tick database for each stocks after deleting errors where negative quotes, negative spreads, or unreasonable quotes are presented. The spread skewness is then computed for daily spreads for the available stocks in each year. The annual skewness is calculated as the equally-weighted average of each stock's skewness in the same year.

\begin{tabular}{ccc}
\hline Year & $\begin{array}{c}\text { Skewness for } \\
\text { Quoted spread }\end{array}$ & $\begin{array}{c}\text { Skewness for } \\
\text { Proportional quoted } \\
\text { spread }\end{array}$ \\
\hline 1997 & -0.1137 & 0.1222 \\
1998 & 0.1369 & 0.3755 \\
1999 & 0.0676 & 0.3924 \\
2000 & 0.0779 & 0.4503 \\
2001 & 0.2207 & 0.4957 \\
2002 & 0.3708 & 0.7189 \\
2003 & 0.5930 & 0.5341 \\
2004 & 0.2788 & 0.3907 \\
2005 & 0.5321 & 0.6064 \\
2006 & 0.7016 & 0.7828 \\
2007 & 0.7057 & 0.8134 \\
2008 & 1.1263 & 1.1637 \\
2009 & 1.0167 & 0.7144 \\
& & \\
$\left(p 0_{2009-1997}\right.$ & 1.0204 & 0.5922 \\
\hline
\end{tabular}

\subsection{Asymmetric Information and Earnings Announcement Effect}

In this section and the ensuing analysis we utilise the daily dataset. We also focus on proportional quoted spreads rather than quoted spreads as the former are more economically meaningful and free from the measurement unit.

We test whether extreme spreads are more likely to be observed during periods of high level of asymmetric information. Glosten and Milgrom (1985) argue that in 


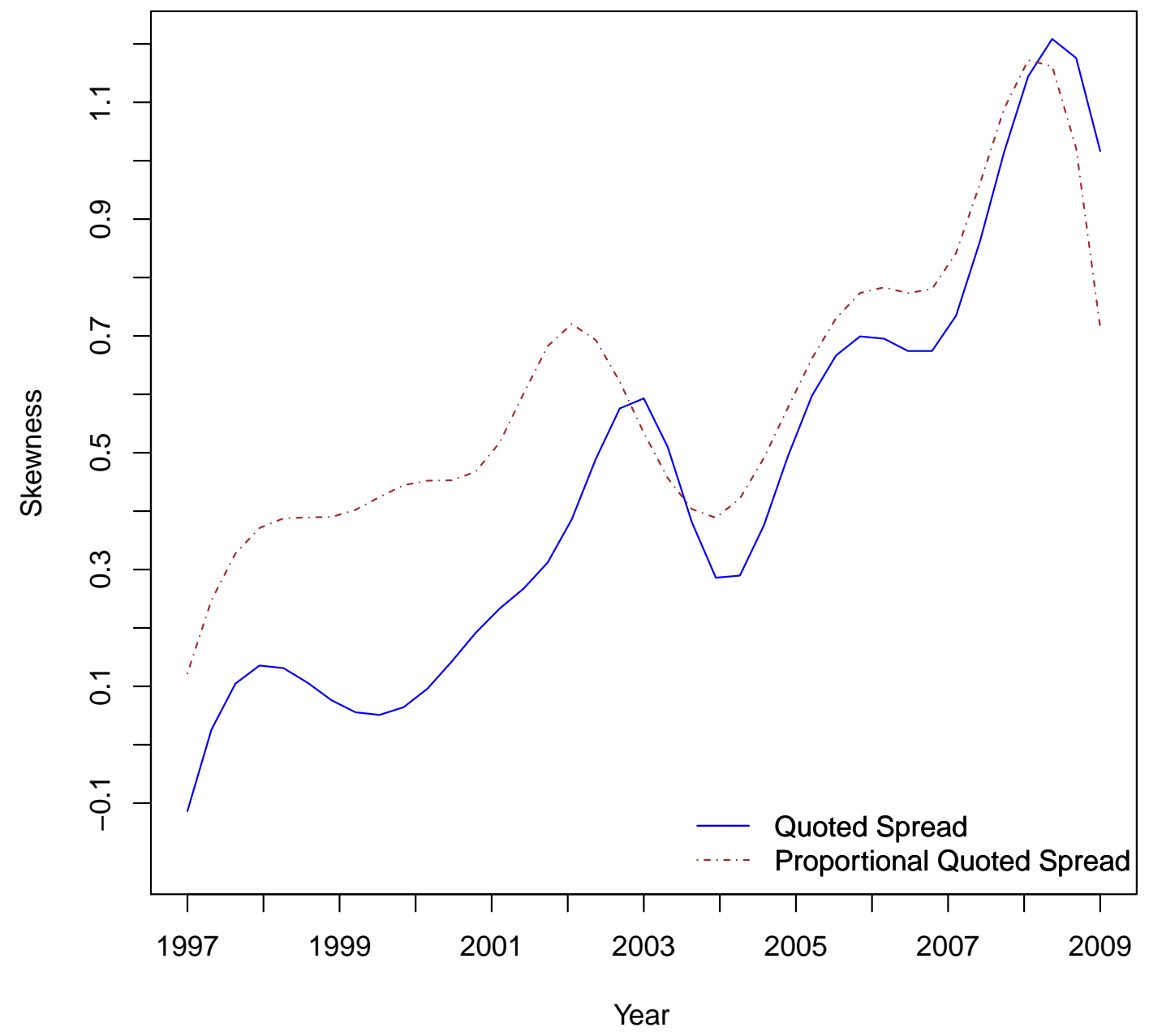

Figure 2: The annual quoted and proportional spread skewness calculated from the tick-by-tick data.

a period of high level of asymmetric information, informed traders make profits from market makers, and market makers who have monopoly power make up the loss by setting a higher bid-ask spread in periods of low level of asymmetric information. In circumstances of heightened competition, market makers lose monopoly power and a minimum guaranteed profit per transaction by way of a larger spread. The 
market maker will also lose the ability to cross-subsidize spreads in periods of high level of asymmetric information by charging higher spreads in periods of low level of asymmetric information. The loss of the ability to cross-subsidize should result in more extreme observations in the right-tail of the distribution of spreads.

Following Roll and Subrahmanyam (2010), we use earnings announcement dates to identify high and low levels of asymmetric information. More specifically, the five days prior to the earnings announcement dates are defined as the period of high level of asymmetric information, while non-announcement dates and the five days following the earnings announcements dates are defined as the period of low level of asymmetric information. We use the average spread over five trading days prior to earnings announcement dates minus the average spread in non-announcement dates in each year, denoted as $I E$. We also calculate differences in the spreads for the five days prior to and the five days following earnings announcement dates, denoted as IE2. Table 4 reports the results.

Panel A shows that the mean difference in spreads for the five days prior to the earnings announcement dates and non-announcement dates is negative across each year. We also calculate changes in skewness between two periods i.e. 2005-2009 and 1999-2004 at the bottom of Panel A. ${ }^{5}$ The results show that such change is statistically significant at a reasonable confidence level. This supports the contention that

\footnotetext{
${ }^{5}$ Our earnings announcement data commences from 1999. The sample is split 1999-2004 and 2005-2009. During the first period the dot-com bubble collapsed (2000-2002), and during the second period the onset of the global financial crisis occurred (2007-2008). Unreported analysis finds that the results are similar when the sample is divided 1999-2003 and 2004-2009. This also holds for the analysis detailed in Table 5 .
} 
asymmetric information is responsible for the increased skewness of bid-ask spreads. In Panel B, we compare the 5-day average spread prior to and following earnings announcements. The results show that the difference in spreads is higher in the preearnings announcement period than in the post earnings announcement period with differences reaching the highest levels in 2007 and 2008. This evidence suggests that extreme market downturns increase the level of asymmetric information. This may be because market makers may have encountered funding constraints during the 2007-2008 crisis given that their ability to provide additional liquidity to the market was largely limited (Brummermeier and Pedersen, 2009). Overall, our findings imply that asymmetric information may be responsible for the increased skewness of bid-ask spreads.

\subsection{Down market effects}

Chordia et al. (2001), Hameed et al. (2001) and Hsieh et al. (2013) find that liquidity declines during a pronounced market downturn. Vayanos (2004) argue that the reduced liquidity can be attributable to market makers holding insufficient collateral. Brummermeier and Pedersen (2009) contend that funding constraints faced by market makers, sudden price drops, and illiquidity in the market can interplay with each other to cause a liquidity spiral. In market downturns, investors face a greater liquidity risk and they cannot sell assets unless they are willing to pay large transaction costs. Thus, shifts in liquidity in extreme market downturns can be 
Table 4: The earnings announcement effects Panel $\mathrm{A}$ is the percentage difference in spreads five days before earnings announcement dates and the other days of the year.

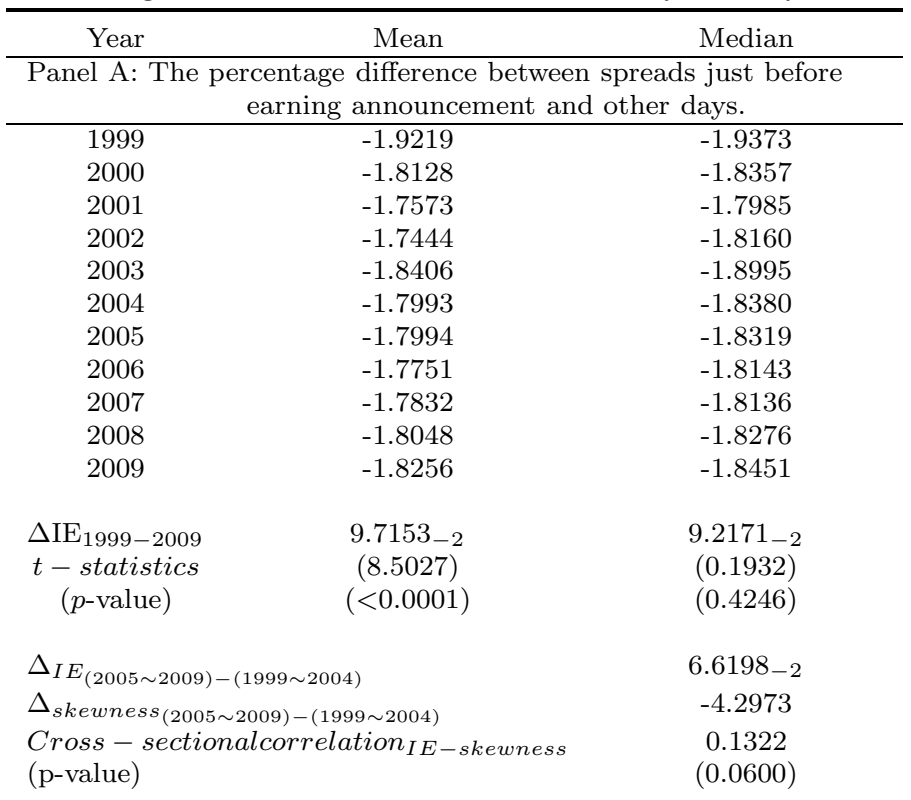

\begin{tabular}{|c|c|c|}
\hline \multicolumn{3}{|c|}{$\begin{array}{c}\text { Panel B: The percentage difference in spreads five days before and } \\
\text { five days after earnings announcement dates }\end{array}$} \\
\hline 1999 & $-1.5192_{-1}$ & $-1.7789_{-1}$ \\
\hline 2000 & $7.8153-2$ & $4.3795-3$ \\
\hline 2001 & $-5.2006_{-3}$ & $2.2500_{-16}$ \\
\hline 2002 & $1.5895-2$ & $3.5354-2$ \\
\hline 2003 & $1.3499-2$ & $-1.4489-2$ \\
\hline 2004 & $2.5485-3$ & $1.6998-4$ \\
\hline 2005 & $3.4924-2$ & $3.4602-2$ \\
\hline 2006 & $1.2482_{-1}$ & $7.4241_{-2}$ \\
\hline 2007 & $1.6461_{-1}$ & $1.1765_{-1}$ \\
\hline 2008 & $1.4990_{-1}$ & $1.2129-1$ \\
\hline 2009 & $2.88498-2$ & 0 \\
\hline 2009-1999 & $1.8077-1$ & $1.7789-1$ \\
\hline$t-$ statistics & 1.9593 & 4 \\
\hline ( $p$-value) & $(0.0333)$ & $(0.0006)$ \\
\hline \multicolumn{2}{|c|}{$\Delta_{I E 2_{2005 \sim 2009-1999 \sim 2004}}$} & 0.2304 \\
\hline \multicolumn{2}{|c|}{$\Delta_{\text {skewness }} 2005 \sim 2009-1999 \sim 2004$} & -4.2973 \\
\hline \multicolumn{2}{|c|}{ Cross-sectional correlation $I E 2-$ skewness } & 0.0543 \\
\hline
\end{tabular}

Subscript $s$ means that the index of scientific notation is to be multiplied by $10^{s}$, for example, $2.2500_{-3}$ is 0.00225 .

responsible for the skewness of bid-ask spreads.

We now analyse the impact of market downturns on the skewness of bid-ask spreads. Specifically, we define trading days within the fifth percentile of returns 
on the FTSE100 index as extreme market downturns. We calculate differences in spreads between trading days within the fifth percentile and other trading days above the sixth percentile, denoted as $E R$. We expect that $E R$ will have an upward trend over time. The results are reported in Table 5 .

The results show that the mean $E R$ is between $1.5 \%$ and $22.34 \%$. The highest ER appears in 2002 when the dot-com bubble burst. Furthermore, the second highest ER occurs in 2008 at the onset of the global financial crisis. These results are consistent with our prior that extreme market downturns significantly increase bid-ask spreads. However, the change in ER between 1997 and 2009 is highly significant, consistent with bid-ask spreads declining. We also show that $E R$ and the skewness have significantly increased from the first sub-period (1997-2003) to the second sub-period (2004-2009). We further show that the correlation between $E R$ and the skewness of the bid-ask spread is also statistically significant. Collectively, our findings suggest that extreme down markets are likely to increase bid-ask spreads and their skewness.

\subsection{Cross-Sectional Determinants}

So far, we find that asymmetric information can explain the skewness of bid-ask spreads over time. In this section, we undertake a cross-sectional analysis to investigate whether asymmetric information, proxied by firm characteristics, can also explain the skewness. Specifically, we run cross-sectional regressions with the skew- 
Table 5: The down-market effect

The percentage difference between spreads in a down market and other market days. The down market is defined as the situation where the market return is less than the 5th percentile of the daily return.

\begin{tabular}{|c|c|c|}
\hline Year & Mean & Median \\
\hline 1997 & 0.0150 & 0.0010 \\
\hline 1998 & 0.0582 & 0.0456 \\
\hline 1999 & 0.0793 & 0.0576 \\
\hline 2000 & 0.1466 & 0.0949 \\
\hline 2001 & 0.1948 & 0.1401 \\
\hline 2002 & 0.2234 & 0.1594 \\
\hline 2003 & 0.1702 & 0.1381 \\
\hline 2004 & 0.1030 & 0.0891 \\
\hline 2005 & 0.0999 & 0.0818 \\
\hline 2006 & 0.1239 & 0.1064 \\
\hline 2007 & 0.1362 & 0.1179 \\
\hline 2008 & 0.1871 & 0.1606 \\
\hline 2009 & 0.0094 & 0.0091 \\
\hline$\Delta E R_{2009-1997}$ & -0.0972 & 0.0922 \\
\hline$t$-statistics & $(8.5027)$ & $(0.1932)$ \\
\hline ( $p$-value $)$ & $(<0.0001)$ & $(0.4246)$ \\
\hline \multicolumn{2}{|c|}{$\Delta_{E R_{(20042009)-(19972003)}}$} & 0.5531 \\
\hline \multicolumn{2}{|c|}{$\Delta_{\text {skewness }}(2004$ 2009)-(1997 2003) } & 4.4210 \\
\hline \multirow{2}{*}{\multicolumn{2}{|c|}{$\begin{array}{l}\text { Cross-sectional correlation }{ }_{E R-s k e w n e s s} \\
\text { ( } p \text {-value) }\end{array}$}} & 0.0951 \\
\hline & & $<0.0001$ \\
\hline
\end{tabular}

ness of bid-ask spreads as the dependent variable. The independent variables include $I E 2$ and $E R$ as previously defined, firm size, return volatility as proxies for information asymmetry. Large and less volatile stocks should have less information opaqueness. In addition, we also include the asynchronicity measure proposed by Hou and Moskowitz (2005) as an explanatory variable. This measure is calculated by one minus $R^{2}$ which is estimated from a regression of stock returns on the FTSE 100 index and the return on the industry portfolio that the stock belongs to. The model is as follows

$$
r_{i}=\alpha_{i}+\beta_{i} r_{i n d_{i}}+\sigma r_{m}+\epsilon
$$


where $r_{i}$ is the return of stock $i, r_{i n d_{i}}$ is the industry portfolio that stock $i$ belongs to, and $r_{m}$ is the market index. We use the ICB industry classification with 41 industries.

In our cross-section regressions, we also include the lagged spread because the level of asymmetric information could correlate with the spread. To control for endogeneity and possible "look-ahead" bias, our independent variables are lagged by one year. Our empirical model is as follows:

$$
\begin{array}{r}
S K_{i, t}=\alpha_{t}+\beta_{1} \text { Vola }_{i, t-1}+\beta_{2} \text { Size }_{i, t-1}+\beta_{3} I E 2_{i, t-1}+\beta_{4} E R_{i, t-1}+ \\
\beta_{5} \text { Asynch }_{i, t-1}+\beta_{6} S P R E A D_{i, t-1}+\varepsilon_{t},
\end{array}
$$

where $S K_{i, t}$ is the skewness of the bid-ask spread of stock $i$ at year $t$, Vola is the daily volatility during the year, Size is market capitalisation at year end, IE2 is the information asymmetry measure defined as before, $E R$ is the measure of extreme market downturns defined as before, Asynch is the Hou and Moskowitz (2005) asynchronicity measure, and $S P R E A D$ is the proportional spread.

Table 6 reports descriptive statistics for the explanatory variables. The average of daily return volatility is 0.0126 with a standard deviation of 0.0118 . The average market capitalisation is $£ 2.41$ million and the standard deviation is $£ 10.2$ million. The mean of information asymmetry related to earnings announcements is 0.075 with a standard deviation of 0.443 . The mean of information asymmetry related to 
extreme market downturns is 0.059 with a standard deviation of 0.242 . The average

value of the asynchronicity measure is 0.557 and its standard deviation is 0.391 .

Table 6: Summary statistics for explanatory variables.

This table summarises the descriptive statistics for cross-sectional determinants of skewness. The determinants include the daily volatility for the year, Vola, between September 1996 and March 2009; Size is the market capitalisation for the previous year; IE2 is the percentage difference in spreads five days after and five days before earnings announcements dates; $E R$ is the percentage difference of the spread between the extreme low returns and other days; Asynch is the asymmetry measure of Hou and Moskowitz (2005), which is one minus the $R^{2}$ of the regression of individual stock returns of the same industry.

\begin{tabular}{ccc}
\hline & Mean & Standard Deviation \\
\hline Vola & $1.26_{-2}$ & $1.18_{-2}$ \\
Size & $2.41_{6}$ & $1.02_{7}$ \\
IE2 & $7.75_{-2}$ & 0.443 \\
ER & $5.85_{-2}$ & 0.2418 \\
Asynch & 0.557 & 0.391 \\
\hline
\end{tabular}

The cross-sectional regression results for Equation (2) are reported in Table 7. The results show that $I E 2$ has a significantly positive coefficient from 2005 to 2008. In addition, the coefficient peaks in 2007 and 2008. This evidence indicates that information asymmetry around earnings announcements significantly raises the skewness of liquidity during the financial crisis, consistent with our information asymmetry based argument. We also find that the lagged spread has a marginal effect on the skewness only in 2007, suggesting that illiquid stocks prior to the crisis are more likely to have right-skewed bid-ask spreads during the crisis. This evidence is consistent with the liquidity spiral hypothesis (Brummermeier and Pedersen, 2009). We also show that the coefficient on size is large and significantly positive in 2008, implying that big firms are likely to have right-skewed bid-spreads during the financial crisis. This evidence contrasts to our expectation that small 
firms should have positive skewness. However, it could be argued that because trading with large firms require market markers to have sufficient capital and if market makers have funding constraints, the bid-ask spreads of large firms are more likely to be affected than those of small firms. Overall, our evidence shows that in times of crisis information asymmetry and the funding constraints of market makers can explain the skewness of bid-ask spreads. 
Table 7: The cross-sectional regressions for skewness.

The summary statistics for the regression of the cross-sectional determinants of skewness.

$$
S K_{i, t}=\alpha_{t}+\beta_{1} \text { Vola }_{i, t-1}+\beta_{2} \text { Size }_{i, t-1}+\beta_{3} I E 2_{i, t-1}+\beta_{4} E R_{i, t-1}+\beta_{5} \text { Asynch }_{i, t-1}+\beta_{6} S P R E A D_{i, t-1}+\varepsilon_{t},
$$

where the dependent variable, $S K_{i, t}$, denotes the averaged skewness for the proportional quoted spreads of stock $i$ in year $t$. Vola is the daily return volatility for the year. Size is the market capitalisation at the previous year end. IE2 is the percentage difference in spreads five days after and five days before the earnings announcement date. $E R$ is the percentage difference of spread between the extreme low returns and other days. Asynch is the Hou and Moskowitz (2005) information asymmetry measure. SPREAD is the average proportional quoted spread over the year. For ease of exposition small numbers are represented in scientific subscript form, for example, $3.65_{-02}$ means 0.0365 .

\begin{tabular}{|c|c|c|c|c|c|c|c|c|c|c|c|c|c|c|}
\hline \multirow[t]{2}{*}{ Year } & \multicolumn{2}{|c|}{ Vola } & \multicolumn{2}{|c|}{ Size } & \multicolumn{2}{|c|}{$I E 2$} & \multicolumn{2}{|c|}{$E R$} & \multicolumn{2}{|c|}{ Asynch } & \multicolumn{2}{|c|}{$S P R E A D$} & \multicolumn{2}{|c|}{ Intercept } \\
\hline & $\beta_{1}$ & $t$-Stats & $\beta_{2}$ & $t$-Stats & $\beta_{3}$ & $t$-Stats & $\beta_{4}$ & $t$-Stats & $\beta_{5}$ & $t$-Stats & $\beta_{6}$ & $t$-Stats & $\alpha$ & $t$-Stats \\
\hline 1999 & -11.34 & -0.56 & $-3.27-08$ & -0.55 & 0.85 & 0.38 & -1.87 & -0.24 & 1.29 & 0.31 & -0.13 & -0.42 & 8.06 & 0.60 \\
\hline 2000 & 3.01 & 0.66 & $1.61_{-08}$ & 0.76 & 1.21 & 1.24 & 2.03 & 0.95 & -2.42 & -0.77 & -0.06 & -1.53 & 4.91 & 1.38 \\
\hline 2001 & -1.12 & -0.76 & $7.73_{-10}$ & 0.09 & -0.28 & -0.21 & 0.21 & 0.13 & 0.43 & 0.26 & -0.02 & -0.71 & 2.65 & 1.71 \\
\hline 2002 & -1.21 & -1.12 & $-1.36_{-08}$ & -1.08 & -0.94 & -0.81 & 3.34 & 2.35 & 1.35 & 0.72 & 0.02 & 0.93 & 1.26 & 0.77 \\
\hline 2003 & -1.14 & -1.30 & $1.13_{-08}$ & 0.72 & -0.52 & -0.74 & 2.17 & 2.69 & -0.22 & -0.18 & -0.004 & -0.19 & 2.23 & 2.14 \\
\hline 2004 & -2.14 & -2.27 & $5.55_{-09}$ & 0.48 & -0.33 & -0.63 & 1.59 & 2.26 & 0.68 & 0.63 & -0.006 & -0.21 & 1.87 & 2.08 \\
\hline 2005 & -2.07 & -3.42 & $-3.84_{-09}$ & -0.33 & 0.93 & 2.20 & -1.88 & -2.77 & -0.10 & -0.10 & -0.02 & -0.92 & 2.65 & 3.00 \\
\hline 2006 & -1.33 & -2.19 & $-8.80-09$ & -0.96 & 0.89 & 2.39 & -1.32 & -2.40 & -0.60 & -0.88 & -0.0006 & -0.04 & 2.67 & 4.84 \\
\hline 2007 & -0.76 & -1.33 & $8.05_{-10}$ & 0.09 & 1.34 & 4.99 & -0.77 & -1.72 & 0.34 & 0.54 & 0.03 & 1.80 & 1.69 & 3.38 \\
\hline 2008 & -0.85 & -1.11 & $5.15_{-08}$ & 3.04 & 1.23 & 2.43 & -1.84 & -2.36 & -3.56 & -3.48 & -0.12 & -3.04 & 6.66 & 8.12 \\
\hline 2009 & -0.20 & -1.02 & $4.05_{-08}$ & 4.39 & -0.05 & -0.33 & -0.63 & -2.52 & -0.26 & -0.66 & -0.008 & -1.61 & 1.82 & 5.30 \\
\hline
\end{tabular}




\section{Conclusion}

Liquidity in financial markets is a key issue for investors, regulators and policy makers. Liquidity risk has an important role in determining transaction costs, enhancing asset management and promoting financial stability. Measuring liquidity by bid-ask spreads, this paper investigates the distribution and dynamics of liquidity in the LSE from 1996 to 2009. We find that bid-ask spreads have sharply declined in our sample period. This evidence suggests that market liquidity on the LSE has significantly improved. We also find that the reduction in bid-ask spreads is large in 2008 and 2009, suggesting that the implementation of MiFID has improved market transparency and reduced transaction costs. However, bid-ask spreads are increasingly right-skewed. In particular, the skewness peaks in 2007 at the outset of the global financial crisis. In that period, large firms are more likely to have right-skewed bidask spreads. These results suggest that market makers may have significant funding constraints in trading large stocks, consistent with the interaction of market liquidity and funding liquidity. Our main findings are robust to firm size, trading volume and price level and are also consistent with the results generated with high frequency data.

Additionally, we find that bid-ask spreads are significantly higher prior to earnings announcements than post earnings announcements and we suggest that this is a consequence of asymmetric information differences. We also find that information asymmetry is more pronounced during the global financial crisis, implying 
that market illiquidity further increases the level of asymmetric information. These results are consistent with the view that competition reduces market makers abilities to influence the bid-ask spread. Our results show that extreme down markets are likely to increase bid-ask spreads and their skewness. Finally, our cross-section analysis examines whether firm-specific characteristics can explain the skewness of bid-ask spreads. We find that the effect of earnings announcements has a significant relationship with the skewness of bid-ask spreads during the crisis period, implying that asymmetric information is amplified by extreme market downturns 


\section{References}

Amihud, Yakov (2002), "Illiquidity and stock returns: cross-section and time-series effects", Journal of Financial Markets, 5(1), 31-56.

Amihud, Yakov and Mendelson, Haim (1986), "Asset pricing and the bid-ask spread", Journal of Financial Economics, 17(2), 223-249.

Bessembinder, Hendrik (2003), "Trade execution costs and market quality after decimalization", Journal of Financial and Quantitative Analysis, 38(4), 747-777.

Bowen, David, Hutchinson, Mark C, and O'Sullivan, Nail (2010), "High frequency equity pairs trading: transaction costs, speed of execution and patterns in returns", Journal of Trading, 5(3), 31-38.

Brummermeier, Markus and Pedersen, Lasse Heje (2009), "Market liquidity and funding liquidity", Review of Financial Studies, 22(6), 2201-2238.

Chordia, Tarum, Roll, Richard, and Subrahmanyam, Avanidhar (2001), "Market liquidity and trading activity", Journal of Finance, 56(2), 501-530.

Glosten, Lawrence R. and Milgrom, Paul R. (1985), "Bid, ask and transaction prices in a specialist market with heterogeneously informed traders", Journal of Financial Economics, 14(1), 71-100.

Hameed, Allaudeen, Kang, Wenjin, and Viswanathan, S. (2010), "Stock market declines and liquidity", Journal of Finance, 65(1), 257-293. 
Hou, Kewei and Moskowitz, Tobias J. (2005), "Market frictions, price delay, and the cross-section of expected returns", Review of Financial Studies, 18(3), 981-1020.

Hsieh, Tsung-Han, Li, Youwei, and McKillop, Donal G. (2013), "Liquidity and financial bubbles in london stock exchange: 1996-2009", in British Accounting and Finance Association (eds.), Procedings of BAFA Annual Conference 2013, New Castle upon Tyne, UK: British Accounting and Finance Association.

Lee, Charles M. C. and Ready, Mark J. (1991), "Inferring trade direction from intraday data", Journal of Finance, 46(2), 733-746.

O'Hara, Maureen (2014), "High-frequency trading and its impact on markets", Financial Analysts Journal, 70(3), 18-27.

Pellizzon, Loriana, Subrahmanyam, Marti G., Tomio, Davide and Uno Jun (2016), "Sovereign credit risk, liquidity, and European Central Bank intervention: Deus ex machina?", Journal of Financial Economics, 122(1), 86-185.

Roll, Richard and Subrahmanyam, Avanidhar (2010), "Liquidity skewness", Journal of Banking and Finance, 34(10), 2562-2571.

Vayanos, Dimitri (2004), "Flight to quality, flight to liquidity, and the pricing of risk", Working paper, London School of Economics. 